\title{
Desenvolvimento, crescimento e produtividade de mandioca em diferentes datas de plantio em região subtropical
}

\author{
Development, growth and yield of cassava in different sowing season in a subtropical region
}

\author{
Lovane Klein Fagundes ${ }^{I}$ Nereu Augusto Streck ${ }^{I *}$ Hamilton Telles Rosa $^{\mathrm{I}}$ Lidiane Cristine Walter $^{\mathrm{III}}$ \\ Alencar Junior Zanon ${ }^{\text {IV }}$ Sidinei José Lopes ${ }^{\text {II }}$
}

\section{RESUMO}

A mandioca é uma cultura de grande importância econômica e social, cultivada em todo o pais, mas em regiões subtropicais precisa ser melhor estudada. O objetivo deste trabalho foi caracterizar alguns parâmetros de desenvolvimento, crescimento e os componentes da produtividade de ramas e de raizes tuberosas de uma variedade de mandioca em várias datas de plantio, em local de clima subtropical. $O$ experimento de campo foi conduzido no ano agrícola de 2006/2007, em Santa Maria, RS, com a variedade de mandioca FEPAGRO RS 13. Os tratamentos foram em quatro datas de plantio (26/09/2006, 18/10/2006, 08/11/2006 e 28/11/2006) na densidade de 16.000 plantas ha-1 e no delineamento inteiramente casualizado com amostragem de seis plantas na parcela. Foram coletadas variáveis de desenvolvimento (datas de estágios de desenvolvimento), crescimento (comprimento e diâmetro de ramos, área foliar e altura de plantas) e componentes da produtividade de caule (rama) e de raizes tuberosas. Plantios mais cedo aumentam a taxa de desenvolvimento até o início da acumulação de amido nas raizes e até o aparecimento da primeira ramificação simpodial. O crescimento dos ramos decresceu com o atraso na data de plantio. Em cada ramificação de primeira e segunda ordem, os ramos tiveram crescimento diferente. A produtividade de raizes tuberosas não foi afetada pela data de plantio.

Palavras-chave: fenologia, área foliar, raizes tuberosas, Manihot esculenta Crantz.

\begin{abstract}
Cassava is an important crop grown in different parts of Brazil, but needs to be more studied in subtropical regions. The objective of this study was to characterize some developmental and growth parameters, and yield components of stem and tuber roots of a cassava variety in several sowing season in a subtropical location. A field experiment was conducted during the 2006/2007 growing season in Santa Maria, RS, Brazil, with the variety FEPAGRO RS 13. Treatments were in four sowing season (26 September 2006, 18 October 2006, 08 November 2006, and 28 November 2006) with a plant density of 16,000 plants $h^{-1}$, in a completely randomized design with six sampling plants inside the plots. Development (date of developmental stages) growth variables (stem length and diameter, leaf area, and plant height), and yield components were measured. Earlier plantings increased the developmental rate until the onset of starch accumulation and until the appearance of sympodial branches. Stems growth decreased as planting was delayed. Stems within first and second order branches had different growth. Tuber roots yield was not affected by the sowing season.
\end{abstract}

Key words: phenology, leaf area, tuber roots, Manihot esculenta Crantz.

\section{INTRODUÇÃO}

O cultivo de mandioca no Brasil é realizado em todas as regiões brasileiras, as quais têm diferentes

'Programa de Pós-graduação em Agronomia, Centro de Ciências Rurais (CCR), Universidade Federal de Santa Maria (UFSM), Santa Maria, RS, Brasil.

"Departamento de Fitotecnia, CCR, UFSM, Av. Roraima, 1000, 97105-900, Santa Maria, RS, Brasil. E-mail: nstreck1@smail.ufsm.br. *Autor para correspondência.

"IIPrograma de Pós-graduação em Engenharia Agrícola, CCR, UFSM, Santa Maria, RS, Brasil.

${ }^{\text {IV }}$ Curso de Agronomia, CCR, UFSM, Santa Maria, RS, Brasil. 
tipos de solo e clima. O Rio Grande do Sul (RS) tem uma pequena participação na produção nacional de mandioca, apenas $7 \%$, concentrada principalmente na região da Depressão Central (CUENCA \& MANDARINO, 2006), que apresenta clima subtropical. Apesar de ser pequena a área com mandioca no RS, essa cultura tem um papel social importante nesse Estado, pois quase toda área cultivada está em pequenas propriedades familiares, como cultivo de subsistência para alimentação animal (raízes e ramas) e humana (raízes) (SCHONS et al., 2009). Na maioria das regiões do Brasil, o plantio da mandioca é realizado no início da estação chuvosa (EMBRAPA, 2003), enquanto no RS o plantio é realizado em setembro e outubro, quando as temperaturas estão em elevação e as gemas, antes dormentes devido às baixas temperaturas invernais, começam a brotar (CONCEIÇÃO, 1981).

Desenvolvimento refere-se à diferenciação celular, iniciação e aparecimento de órgãos, enquanto que crescimento é o aumento irreversível de uma grandeza física como massa, área, altura e diâmetro. No $\mathrm{RS}$, as plantas de mandioca perdem as folhas e paralisam seu crescimento durante o inverno. Esse fato marca o seu repouso invernal e, assim que as temperaturas aumentam na primavera e tornam-se favoráveis para a brotação das gemas, reinicia-se o ciclo de crescimento. Informações sobre datas de plantio da mandioca no RS são escassas (SCHONS et al., 2007), especialmente no que se refere às variáveis de desenvolvimento e crescimento visando a maiores produtividades da parte aérea e raízes tuberosas, o que constitui a motivação para esta pesquisa.

O objetivo deste trabalho foi caracterizar alguns parâmetros de desenvolvimento, de crescimento e os componentes da produtividade de ramas e de raízes tuberosas de uma variedade de mandioca em várias datas de plantio, em local de clima subtropical.

\section{MATERIAL E MÉTODOS}

O experimento foi conduzido durante $\mathrm{o}$ ano agrícola 2006/2007 na área do Departamento de Fitotecnia da Universidade Federal de Santa Maria, em Santa Maria, RS, (latitude: $29^{\circ} 43^{\prime}$ S, longitude: $53^{\circ} 43^{\prime} \mathrm{W}$ e altitude: $95 \mathrm{~m}$ ), localizada na região fisiográfica da Depressão Central do RS. A região possui clima $\mathrm{Cfa}$ (subtropical úmido sem estação seca definida e com verões quentes), segundo a classificação de Köppen.

Os tratamentos foram em quatro datas de plantio: 26/09/2006, 18/10/2006, 08/11/2006 e28/11/2006. As duas primeiras estão situadas dentro da época recomendada, que é em setembro e outubro (CONCEIÇÃO, 1981), as duas últimas são consideradas tardias para a região. A variedade usada foi a FEPAGRO RS 13, recomendada para mesa, adaptada e bastante usada no RS, com caule simpodial tricotômico (FEPAGRO, 2005). O delineamento experimental foi o inteiramente casualizado, com quatro repetições e amostragem na parcela. A área foi dividida em quatro partes onde foram distribuídos os tratamentos (datas de plantio). Cada parte foi subdividida em quatro parcelas, com área de $4,0 \mathrm{~m} \times 9,0 \mathrm{~m}$, com cinco fileiras de $9,0 \mathrm{~m}$ de comprimento, das quais foram avaliadas seis plantas. A densidade foi de 16.000 plantas $\mathrm{ha}^{-1}$, no espaçamento de $0,80 \mathrm{~m} \times 0,80 \mathrm{~m}$. Adjacentes às áreas das datas de plantio, foram plantadas três fileiras de $22 \mathrm{~m}$ de comprimento, que foram usadas para determinar o início de acumulação de amido (IAA).

O solo foi preparado com duas gradagens e adubação NPK com a fórmula 05-20-20 (275kg ha-1). O plantio foi realizado em covas feitas manualmente, na profundidade de $0,10 \mathrm{~m}$, usando-se manivas-semente de $0,20 \mathrm{~m}$. Foram realizadas duas adubações de nitrogênio em cobertura, uma no IAA (aos 64, 62, 64 e 57 dias após o plantio em cada uma das datas de plantio) e outra 40 dias após a primeira aplicação, na dose de $40 \mathrm{~kg} \mathrm{ha}^{-1}$ cada. Houve controle de plantas daninhas realizado manualmente e não foram feitas irrigações e nem aplicações de inseticidas.

A data da emergência foi considerada quando $50 \%$ das plantas estavam visíveis acima do solo. Uma semana após a emergência, foram selecionadas aleatoriamente seis plantas em cada parcela, totalizando 24 plantas em cada data de plantio. Nestas, foram identificadas, com arames coloridos, a haste principal (HP) e os três ramos do simpódio de primeira ordem (RS1), de segunda ordem (RS2) e de terceira ordem (RS3).

As variáveis de desenvolvimento, medidas nas plantas marcadas, foram: data de IAA e de aparecimento das ramificações RS1, RS2 e RS3. Para determinar o IAA, foi feito o arranquio de seis plantas de mandioca aleatoriamente e diariamente nas três fileiras plantadas para essa análise, sendo o IAA considerado o dia em que pelo menos $50 \%$ das plantas amostradas apresentavam pelo menos uma raiz com diâmetro igual ou superior a $0,01 \mathrm{~m}$ (SCHONS et al, 2009). A duração das fases plantio à emergência (PL-EM), EM ao início de acumulação de amido (EM-IAA), IAA à ramificação simpodial de primeira ordem (IAA-RS1), RS1 à ramificação simpodial de segunda ordem (RS1RS2) e RS2 à ramificação simpodial de terceira ordem (RS2-RS3) foi expressa em ${ }^{\circ} \mathrm{C}$ dia. A soma térmica diária (STd, ${ }^{\circ} \mathrm{C}$ dia) foi calculada por: $\mathrm{STd}=(\mathrm{Tm}-\mathrm{Tb}) .1 \mathrm{dia}$, em que Tm é a temperatura média diária do ar, calculada pela média aritmética das temperaturas mínima e máxima 
do ar e $\mathrm{Tb}$ é a temperatura base, considerada $14^{\circ} \mathrm{C}$ (SCHONS et al., 2007). A soma térmica acumulada (STa, ${ }^{\circ} \mathrm{C}$ dia) para cada fase foi calculada por: $\mathrm{STa}=\Sigma \mathrm{STd}$.

As variáveis de crescimento nas plantas marcadas foram: área foliar, comprimento final da HP e das ramificações RS1 e RS2, altura final da planta do nível do solo até a inserção da última folha e diâmetro final a 0,20m do início da inserção da HP, RS1 e RS2. A área foliar foi determinada a cada duas semanas, medindo-se o comprimento do maior lóbulo nas folhas verdes em uma das plantas marcadas de cada tratamento. A área de cada folha (AF) $\mathrm{em}^{\mathrm{cm}^{2}}$ foi estimada pela equação (SCHONS et al., 2009), em que $\mathrm{AF}=3,2792 \mathrm{x}+0,1607 \mathrm{x}^{2}+0,0402 \mathrm{x}^{3}$, sendo $\mathrm{x}$ o comprimento do maior lóbulo $(\mathrm{cm})$. O índice de área foliar (IAF) verde foi calculado somando-se as áreas individuais de folhas e dividindo-se pela área de solo ocupada por uma planta $\left(0,64 \mathrm{~m}^{2}\right)$.

A colheita foi realizada no dia 19 de junho de 2007 e nessa etapa foi retirada uma amostra de $20 \mathrm{~cm}$ de ramas da HP, RS1, RS2 e RS3 em três plantas por parcela. Essa amostra foi pesada para determinação da massa fresca (MFamostra) e colocada em estufa de ar forçado, à temperatura de $60^{\circ} \mathrm{C}$ até massa constante, para determinação da massa seca (MSamostra). A massa seca da rama (MSrama) foi calculada por: MSrama (g/ planta $)=($ MFamostra $*$ MSamostra $) /$ MFamostra As raízes tuberosas foram contadas e classificadas em comercializáveis (RC) e não comercializáveis (RNC), segundo os critérios usados por SCHONS et al. (2009). Foram tomadas ao acaso $10 \mathrm{RC}$ e $10 \mathrm{RNC}$, pesadas e colocadas em estufa a $60^{\circ} \mathrm{C}$ até massa constante. A massa fresca (MF) e massa seca (MS) de raízes foram calculadas por: MFraízes $\left(\mathrm{g}\right.$ planta $\left.{ }^{-1}\right)=[$ número de raízes
(RC e RNC)/planta]*[ (MF de 10 Raízes)/10 raízes] e MSraízes $\left(\mathrm{g}\right.$ planta $\left.{ }^{-1}\right)=$ [número de raízes $(\mathrm{RC}$ e $\mathrm{RNC}) /$ planta]*[(MS de 10 Raízes)/10 raízes] (SCHONS et al., 2009). A produtividade de ramas, de raízes, RC e RNC, em massa fresca e massa seca $\left(\mathrm{t} \mathrm{ha}^{-1}\right)$ foram calculadas multiplicando-se a massa fresca e seca por planta pela densidade de plantas.

As temperaturas mínima e máxima diárias do ar, durante o período experimental, foram medidas na Estação Climatológica Principal, 8o DISME/INMET, localizada a aproximadamente $100 \mathrm{~m}$ da área experimental. Uma análise estatística objetivou verificar diferenças de comprimento final e diâmetro final de um ramo (i) entre as ramificações (HP, RS1, RS2) e (ii) entre os ramos dentro do mesmo simpódio (RS1 e RS2). Para alcançar (i) considerou-se um bifatorial (quatro datas de plantio x três ramificações). Para alcançar (ii), considerou-se um fatorial hierárquico para os ramos de um mesmo simpódio. As médias da análise bifatorial foram comparadas pelo teste de Tukey e as médias do fatorial hierárquico foram comparadas pelo teste $\mathrm{F}$, ambos a $5 \%$ de probabilidade. A outra análise estatística objetivou testar as médias das outras variáveis de crescimento (altura final, MS e MF de ramas) e das variáveis de produtividade (ramas e raízes tuberosas), considerando-se um experimento em delineamento inteiramente casualizado, comparando-se pelo teste de Tukey a $5 \%$ de probabilidade.

\section{RESULTADOS E DISCUSSÃO}

A duração $\left({ }^{\circ} \mathrm{C}\right.$ dia $)$ das fases PL-EM e EMIAA aumentou com o atraso na data de plantio (Figura 1); variando de $93,1^{\circ} \mathrm{C}$ dia a $115,2^{\circ} \mathrm{C}$ dia e de $456,6^{\circ} \mathrm{C}$

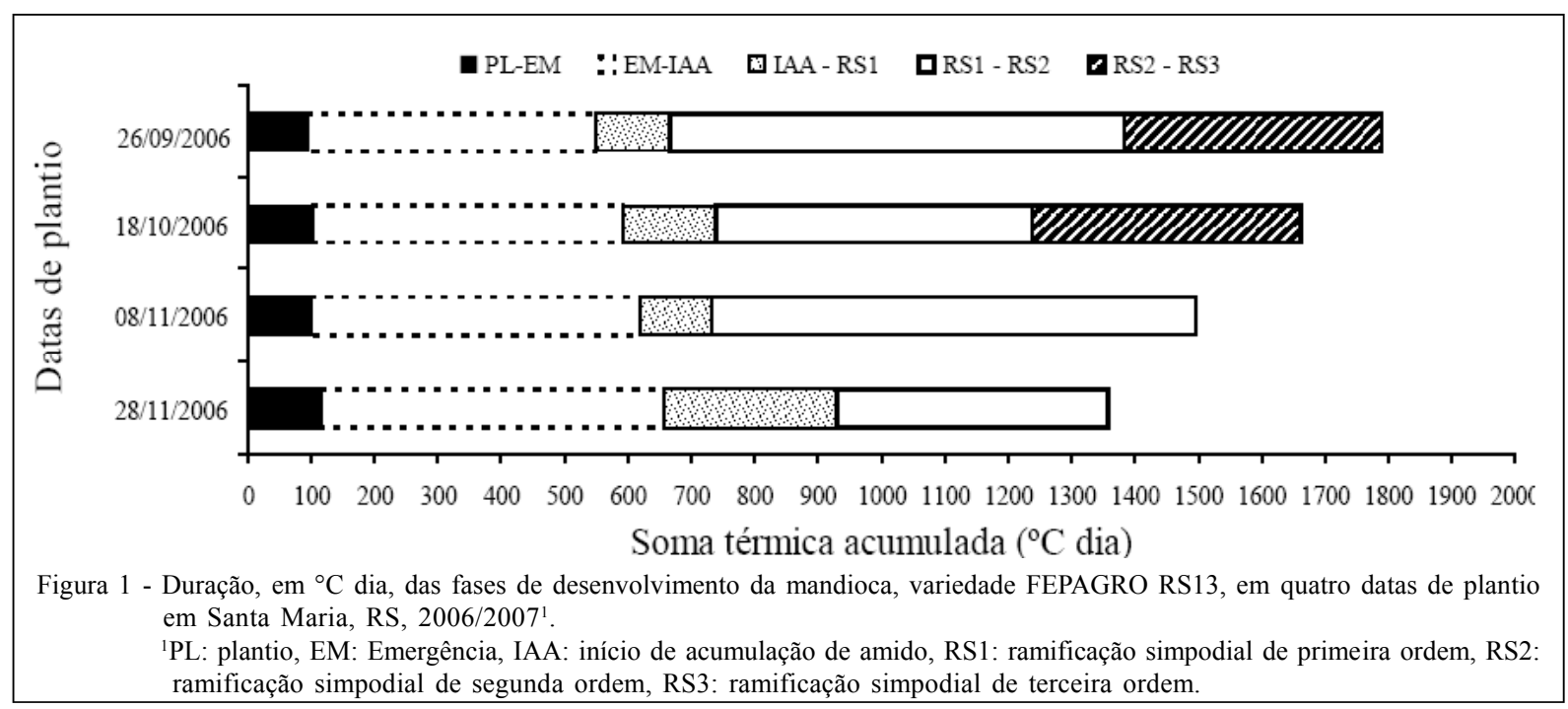

Ciência Rural, v.40, n.12, dez, 2010. 
dia a $540,0^{\circ} \mathrm{C}$ dia, respectivamente. Também foi crescente o número médio de folhas na HP no IAA $\left(30,2 ; 33,5 ; 33,6\right.$ e 36,2 folhas planta $\left.^{-1}\right)$ nas quatro datas de plantio, indicando que, com o atraso no plantio, as plantas emitem mais folhas e acumulam uma soma térmica maior para o IAA. A soma térmica para a fase IAA-RS 1 foi menor nos plantios de $08 / 11 / 2006\left(112^{\circ} \mathrm{C}\right.$ dia) e $26 / 09 / 2006\left(118^{\circ} \mathrm{C}\right.$ dia $)$, intermediário em $18 / 10 /$ $2006\left(145,75^{\circ} \mathrm{C} \mathrm{dia}\right)$ e maior em $28 / 11 / 2006\left(274,8^{\circ} \mathrm{C} \mathrm{dia}\right)$, não seguindo uma tendência clara de aumento ou redução nas diferentes datas de plantio. Na fase RS1$\mathrm{RS} 2$, a soma térmica também não teve uma tendência clara de variação com as datas de plantio, mas teve relação inversa com a duração da fase IAA-RS1, ou seja, foi maior nos plantios de $08 / 11 / 2006\left(764,7^{\circ} \mathrm{C}\right.$ dia $)$ e $26 / 09 / 2006\left(702,2^{\circ} \mathrm{C}\right.$ dia $)$, intermediário no plantio de $18 / 10 / 2006\left(496,15^{\circ} \mathrm{C}\right.$ dia $)$ e menor no plantio de $28 / 11 /$ $2006\left(442,8^{\circ} \mathrm{C} \mathrm{dia}\right)$, indicando sincronismo no desenvolvimento destas duas ramificações simpodiais. Nas duas últimas datas de plantio, as plantas não emitiram a terceira ramificação simpodial antes do repouso invernal, sendo a duração da fase RS2-RS3, de $421,7^{\circ} \mathrm{C}$ dia e $440,6^{\circ} \mathrm{C}$ dia para as duas primeiras datas de plantio, respectivamente.

A evolução do IAF verde durante a estação de crescimento nas quatro datas de plantio é apresentada na figura 2. O IAF máximo foi maior no plantio mais cedo (26/09/2006), cujo valor foi 7,7 e decresceu para 6,7 e 5,6 nas duas datas seguintes (18/
10 e 08/11/2006). Já na data de plantio mais tarde (28/ 11/2006), o IAF máximo foi também elevado $(7,4)$, próximo do IAF máximo da primeira data de plantio. Este elevado IAF, alcançado na data de plantio mais tardia, foi inesperado e se explica pela baixa senescência das folhas basais, comparada com as outras três datas de plantio. Os valores máximos de IAF obtidos neste estudo são superiores aos obtidos por TÁVORA et al. (1995) em um experimento com dez variedades de mandioca no litoral do Ceará (região tropical). $\mathrm{Na}$ pesquisa citada, os valores máximos de IAF aos 309 dias após o plantio variaram de 1,29 a 2,83 e foram similares aos resultados obtidos por BAKER et al. (1989) para uma variedade de mandioca cultivada em região subtropical, cujo IAF máximo foi de 8,0 aos 168 dias após o plantio e diminuiu para um IAF máximo de 3,0 aos 234 dias. Segundo COCK et al. (1979), altas produtividades de raízes de mandioca são alcançadas com um IAF em torno de 3,5 logo após a emergência. Além disso, esse valor deve ser mantido por um longo período de tempo, ao passo que IAF maior que 4,0 tende a reduzir o crescimento de raízes em detrimento da parte aérea.

O decréscimo do IAF após ter atingido o valor máximo, em todas as datas de plantio, (Figura 1) ocorreu devido à progressiva senescência das folhas inferiores do dossel e redução da emissão de folhas novas, a partir do primeiro decêndio de março/2007. Isso aconteceu em decorrência da redução da

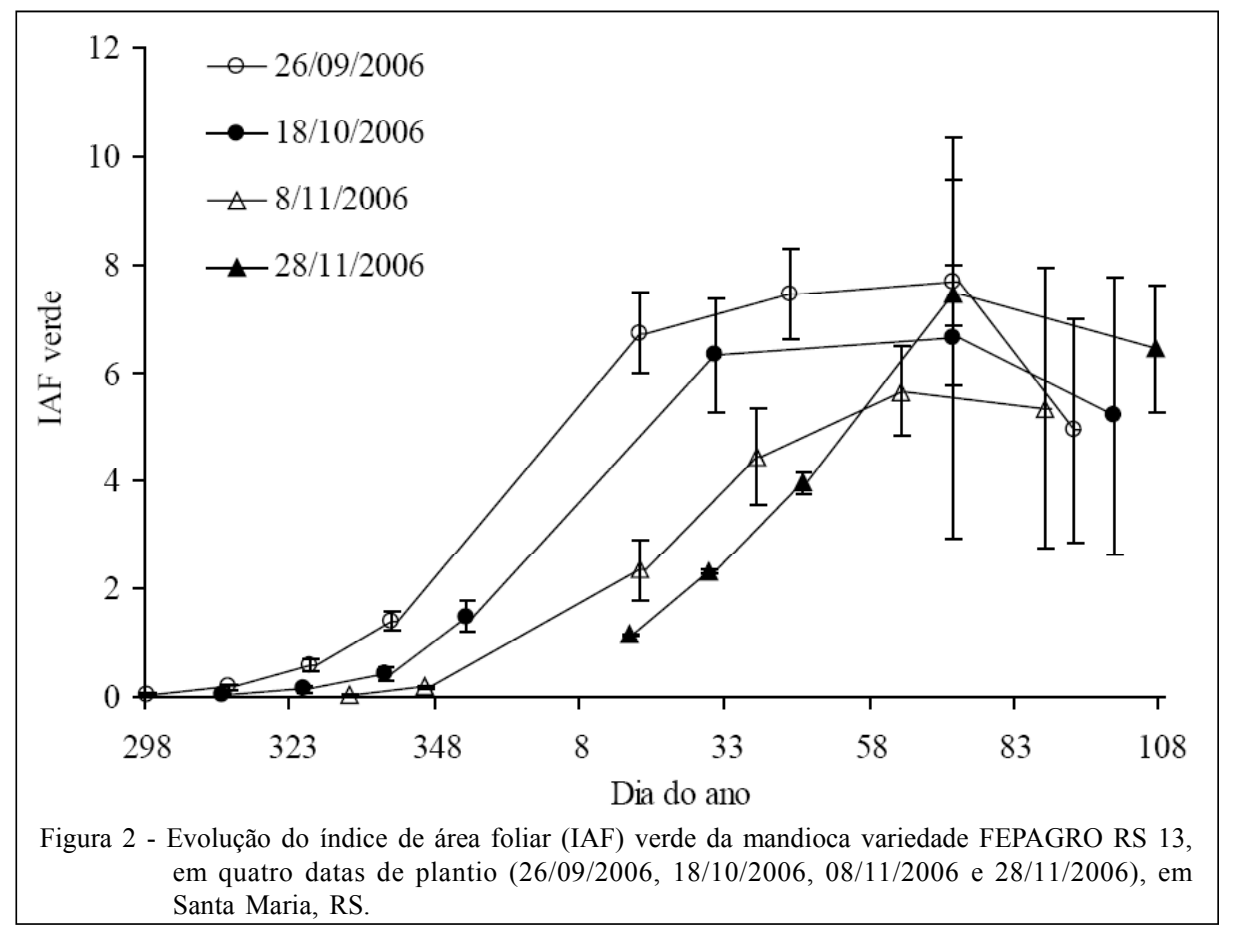

Ciência Rural, v.40, n.12, dez, 2010. 
temperatura do ar e da densidade de fluxo de radiação solar global incidente, com a aproximação do equinócio de outono e do solstício de inverno, fato que levou as plantas de todas as datas de plantio a ter as folhas senescidas até o final de junho de 2007.

Houve interação entre os fatores (data de plantio e ramificações) para a variável comprimento final de ramos, mas não para a variável diâmetro final de ramos. Assim, a análise estatística foi desdobrada para a primeira variável e não para a segunda variável (Tabela 1). Entre as datas de plantio, o comprimento da HP foi menor na primeira data, que diferiu das demais. O menor comprimento da HP no plantio mais cedo está associado com um menor número de folhas nesta data de plantio (42 folhas) comparado com as outras (48, 73 e 62 folhas). Já o comprimento da RS1 foi maior na primeira data de plantio, seguido da quarta e segunda datas, que não diferiram entre si. Por outro lado, a segunda data não diferiu da terceira. O comprimento da RS2 foi maior na primeira data, que diferiu das demais, seguida da segunda data, que, por sua vez, diferiu da terceira e quarta datas de plantio, pois apresentaram os menores valores para a caracterísica (Tabela 1). Menores comprimentos dos ramos da RS1 e, principalmente, de RS2 do que da HP em plantios mais tardios podem estar associados à menor densidade de fluxo de radiação solar incidente durante o crescimento desses ramos, comparado com o plantio mais cedo. Entre as ramificações, o maior comprimento final da HP foi nos dois plantios intermediários, os quais diferiram do plantio mais tardio, sendo que o menor foi o plantio mais no cedo. Para RS1 e RS2, observou-se o inverso, ou seja, maiores valores no plantio mais cedo e menores na terceira data (RS1) e na terceira e quarta datas (RS2).

$\mathrm{O}$ diâmetro final dos ramos foi maior na primeira data de plantio, seguido da segunda e quarta datas, que não diferiram entre si, mas diferiram da terceira data, a qual teve o menor diâmetro (Tabela 1). O maior diâmetro final dos ramos foi na HP, seguido da RS1 e da RS2 (Tabela 1). Maiores diâmetros em plantios mais cedo e entre ramificações, na HP, devem estar associados com maior radiação solar incidente durante o crescimento dos ramos nos plantios mais cedo, bem como ao maior tempo de acumulação de carboidratos na HP.

$\mathrm{Na}$ análise do fatorial hierárquico para ramos de um mesmo nível de simpódio (RS1 e RS2), houve efeito significativo do fator ramo para as variáveis comprimento final de ramos da RS1 e diâmetro final de ramos da RS1 e RS2, mas não houve diferenças significativas para a variável comprimento final de ramos da RS2. Esses resultados indicam que o crescimento de pelo menos um dos três ramos que compõem a RS1 e a RS2, nessa variedade, é diferente.

A altura final das plantas foi maior nas primeiras datas $(3,67 \mathrm{~m} \mathrm{a} 3,41 \mathrm{~m})$, que não diferiram entre si, e menor nas últimas datas de plantio (2,90m e 2,87m), que também não diferiram entre si. Esses valores indicam elevado porte aéreo dessa variedade, comparado com valores de um ensaio em Araruna, noroeste do Paraná, onde a média da altura final de plantas na colheita, em nove variedades de mandioca, foi de $2,27 \mathrm{~m}$ (VIDIGAL FILHO et al., 2000).

A produtividade de massa fresca e de massa seca de ramas foi maior na primeira data, seguida da segunda data, e pelas duas últimas datas de plantio, que não diferiram entre si (Tabela 2). $O$ decréscimo da produtividade de ramas com o atraso do plantio está associado com o progressivo decréscimo do IAF máximo nas primeiras três datas de plantio (Figura 1), pois quanto maior o IAF, maior é produção de fotoassimilados disponíveis para crescimento dos

Tabela 1 - Comprimento final e diâmetro final (cm) do ramo na haste principal (HP), na ramificação simpodial de primeira ordem (RS1) e na ramificação simpodial de segunda ordem (RS2), em função da data de plantio da mandioca, variedade FEPAGRO RS13, em Santa Maria, RS, 2006/2007'.

\begin{tabular}{|c|c|c|c|c|}
\hline \multirow{2}{*}{ Datas de plantio } & & $\mathrm{mit}$ & & \multirow{2}{*}{ Diâmetro final $(\mathrm{cm})$} \\
\hline & HP & RS1 & RS2 & \\
\hline $26 / 09 / 2006$ & $78 \mathrm{Bc}$ & $193 \mathrm{Aa}$ & $83 \mathrm{Ba}$ & $1,9 \mathrm{a}$ \\
\hline $18 / 10 / 2006$ & $168 \mathrm{Aa}$ & $111 \mathrm{Bbc}$ & $54 \mathrm{Cb}$ & $1,5 \mathrm{~b}$ \\
\hline $08 / 11 / 2006$ & $167 \mathrm{Aa}$ & $97 \mathrm{Bc}$ & $37 \mathrm{Cc}$ & $1,2 \mathrm{c}$ \\
\hline $28 / 11 / 2006$ & $132 \mathrm{Ab}$ & $118 \mathrm{Ab}$ & $39 \mathrm{Bc}$ & $1,4 \mathrm{~b}$ \\
\hline \multicolumn{5}{|c|}{ Diâmetro final $(\mathrm{cm})$} \\
\hline & $3,2 \mathrm{~A}$ & $1,6 \mathrm{~B}$ & $0,7 \mathrm{C}$ & \\
\hline
\end{tabular}

Médias seguidas pela mesma letra maiúscula na horizontal e minúscula na vertical não diferem pelo teste de Tukey a $5 \%$ de probabilidade de erro.

Ciência Rural, v.40, n.12, dez, 2010. 
Tabela 2 - Produtividade, massa fresca e massa seca, de ramas e de raízes tuberosas da mandioca, variedade FEPAGRO RS13, em Santa Maria, RS, 2006/2007'.

\begin{tabular}{|c|c|c|c|c|c|c|c|c|}
\hline \multirow{2}{*}{ Datas de plantio } & \multicolumn{4}{|c|}{----------Massa fresca (toneladas ha $\left.{ }^{-1}\right)^{2}-$} & \multicolumn{4}{|c|}{--------Massa seca (toneladas ha $\left.{ }^{-1}\right)^{2}$} \\
\hline & Ramas & $\mathrm{RC}$ & $\mathrm{RNC}$ & Total & Ramas & $\mathrm{RC}$ & $\mathrm{RNC}$ & Total \\
\hline $26 / 09 / 2006$ & 54,9 a & 24,3 a & $0,81 \mathrm{a}$ & $25,2 \mathrm{a}$ & $12,3 \mathrm{a}$ & $8,6 \mathrm{a}$ & $0,31 \mathrm{a}$ & 8,9 a \\
\hline $18 / 10 / 2006$ & $34,8 \mathrm{~b}$ & 36,0 a & $2,0 \mathrm{a}$ & $38,0 \mathrm{a}$ & $8,3 \mathrm{~b}$ & $12,8 \mathrm{a}$ & 0,5 a & $13,3 \mathrm{a}$ \\
\hline $08 / 11 / 2006$ & $23,1 \mathrm{c}$ & $31,5 \mathrm{a}$ & $1,5 \mathrm{a}$ & $33,0 \mathrm{a}$ & $4,4 \mathrm{c}$ & 8,6 a & $0,53 \mathrm{a}$ & $11,3 \mathrm{a}$ \\
\hline $28 / 11 / 2006$ & $24,2 \mathrm{c}$ & $26,2 \mathrm{a}$ & $1,4 \mathrm{a}$ & $27,5 \mathrm{a}$ & $5,4 \mathrm{c}$ & $8,4 \mathrm{a}$ & $0,39 \mathrm{a}$ & $8,8 \mathrm{a}$ \\
\hline $\mathrm{CV} \%$ & 9,9 & 23,3 & 22,1 & 21,1 & 17,9 & 23,2 & 22,2 & 22,1 \\
\hline
\end{tabular}

${ }^{1}$ Médias seguidas pela mesma letra na vertical não diferem pelo teste de Tukey a $5 \%$ de probabilidade de erro. ${ }^{2}$ (RC: raízes comerciais, RNC: raízes não comerciais, Total: $\mathrm{RC}+\mathrm{RNC}$ ).

diferentes compartimentos da planta. Na data de plantio mais tardia (28/11/2006), o IAF máximo alcançou rapidamente valores similares ao IAF da data mais cedo (26/09/2006) e esse fato certamente contribuiu para que o crescimento das ramas fosse similar (e não inferior, como esperado) à produtividade de ramas na terceira data de plantio.

A produtividade de massa fresca e massa seca de raízes tuberosas ( $\mathrm{RC}, \mathrm{RNC}$ e total) não diferiram entre as datas de plantio (Tabela 2). Foi surpreendente a baixa produtividade de raízes no plantio mais cedo (26/09/2006), que pode ser explicada pelo elevado crescimento de ramas e pelo elevado IAF máximo, os quais devem ter causado elevada competição intraespecífica e sombreamento, respectivamente, resultando em menor acúmulo de reservas nas raízes. ALVES (2006) confirma essa hipótese de que, com o sombreamento, há uma limitação da fotossíntese e grande parte dos fotoassimilados é destinada para o crescimento da parte aérea, diminuindo o crescimento das raízes de reserva, indicando que as hastes e folhas são drenos mais fortes do que as próprias raízes. Assim, uma estratégia de manejo para se obter maior produtividade de raízes com esta variedade em plantios cedo no Rio Grande do Sul seria optar por espaçamentos maiores do que $0,8 \mathrm{~m} \times 0,8 \mathrm{~m}$. Por outro lado, quando há interesse do agricultor em usar a parte aérea para o arraçoamento animal, o plantio cedo desta variedade permite um elevado crescimento da parte aérea, sem redução significativa da produtividade de raízes tuberosas.

\section{CONCLUSÃO}

Plantios mais cedo aceleram o desenvolvimento até o início da acumulação de amido e até a ramificação simpodial de primeira ordem na mandioca variedade FEPAGRO RS 13, enquanto o crescimento em comprimento e diâmetro da HP e dos ramos das ramificações simpodiais decresce com o atraso na data de plantio. Entre as ramificações, o crescimento é decrescente na sequência $\mathrm{HP}>\mathrm{RS} 1>\mathrm{RS} 2$. Dentro de cada ramificação simpodial de primeira e segunda ordem, os ramos têm crescimento diferente.

A produtividade das ramas decresce com $o$ atraso na data de plantio, enquanto a produtividade de raízes tuberosas não é afetada por essa data.

\section{REFERÊNCIAS}

ALVES, A.A.C. Fisiologia da mandioca. In: EMBRAPA Mandioca e Fruticultura Tropical. Aspectos socioeconômicos e agronômicos da mandioca. Cruz das Almas, BA: EMBRAPA, 2006. Cap.7, p.138-169.

BAKER, G. R. et al. The response of cassava to water deficits at various stages of growth in the subtropics. Journal of Agricultural Research, v.40, n.1, p.517528, 1989. Disponível em: <http://www.publish.csiro.au/ paper/AR9890517.htm >. Acesso em: 11 dez. 2008. doi: 10.1071/AR9890517.

CONCEIÇÃO, A. J da. A mandioca. São Paulo: Nobel, 1981. $382 \mathrm{p}$.

COCK, J.H. et al. The ideal cassava plant for maximum yield. Crop Science, v.19, p.271-279, 1979.

CUENCA, M.A.G.; MANDARINO D.C. Aspectos agroeconômicos da cultura da mandioca: características e evolução da cultura no Estado do Sergipe entre 1990 e 2004. Aracaju: Embrapa, 2006. 21p. (Documentos, 98).

EMBRAPA. Mandioca e Fruticultura: cultura da mandioca. 2003. On line. Disponível em: <http:// sistemasdeproducao.cnptia.embrapa.br/FontesHTML/Mandioca/ mandioca_centrosul/plantio.htm>. Acesso em: 4 maio, 2007.

FEPAGRO. Novas cultivares para o Rio Grande do Sul: mandioca. Taquarí, RS: Fepagro, 2005. 3p.

SCHONS, A. et al. Emissão de folhas e início da acumulação de amido em raízes de uma variedade de mandioca em função da 
época de plantio. Ciência Rural, v.37, n.6, p.1586-1592, 2007. Disponível em: <http://www.scielo.br/pdf/cr/v37n6/ a13v37n6.pdf>. Acesso em: 13 fev. 2009. doi: 10.1590/S010384782007000600013 .

SCHONS, A. et al. Arranjos de plantas de mandioca e milho em cultivo solteiro e consorciado: crescimento, desenvolvimento e produtividade. Bragantia, v.68, n.1, p.165-177, 2009. Disponível em: <http://www.scielo.br/pdf/brag/v68n1/ a17v68n1.pdf>. Acesso em: 21 mar. 2009. doi: 10.1590/ S0006-87052009000100017.

VIDIGAL FILHO, P.S. et al. Avaliação de cultivares de mandioca na Região Noroeste do Paraná. Bragantia, v.59, n.1, p.6975, 2000. Disponível em: <http://www.scielo.br/pdf/brag/v59n1/ 591a10.pdf $>$. Acesso em: 21 fev. 2009. doi: 10.1590/S000687052000000100011 . 